\title{
A política patrimonial atual do Brasil e a gestão compartilhada do patrimônio arqueológico na Amazônia
}

\author{
The present heritage policy of Brazil and the shared management of \\ the archaeological heritage in the Amazon
}

\author{
Enviado em: 27/04/2017 \\ Aceito em: 14/01/2018 \\ SILVA ,Ana Cristina Rocha ${ }^{1}$ \\ SIMONIAN, Ligia Terezinha Lopes²
}

\begin{abstract}
Resumo:
O artigo aborda as relações entre a trajetória da política de preservação cultural do Brasil e a gestão do patrimônio arqueológico na Amazônia. O objetivo é refletir os reflexos da reorientação metodológica da política patrimonial no gerenciamento dos bens arqueológicos na região, de modo a discutir as modalidades com que o poder público fomenta a apropriação desses bens culturais, aliada aos pilares do desenvolvimento sustentável. As análises fundamentam-se na realidade de três regiões: Maracá (AP); Calçoene (AP); e Monte Alegre (PA). Concluiu-se que a reorientação metodológica da política patrimonial não sinaliza ressonância na constituição de uma gestão densa e efetiva para o patrimônio arqueológico nessas regiões. Ao perpetuar práticas centralizadoras e seletivas, a gestão do bem destacado reproduz a lógica tradicional da política do patrimônio. Dificulta, assim, que a sociedade civil possa conduzir e protagonizar o processo de apropriação de seu meio ambiente cultural.
\end{abstract}

Palavras-chave:patrimônio arqueológico; políticade gestão;

\footnotetext{
1 Doutoranda em Desenvolvimento Socioambiental pelo Programa de Pós-Graduação em Desenvolvimento Sustentável do Trópico Úmido, do Núcleo de Altos Estudos Amazônicos da Universidade Federal do Pará (PPGDSTU/NAEA/UFPA) (2017/...). Mestre em Direito Ambiental e Políticas Públicas pela Universidade Federal do Amapá (2014). Licenciada e Bacharel em História pela Faculdade de Macapá (2009). Especialista em História da Amazônia pela Faculdade de Macapá (2011). É professora Assistente II do Curso de Licenciatura em História da Universidade Federal do Amapá (Campus Binacional).

2 Doutora em Antropologia pela City University of New York (1993) e pós-doutorado nessa mesma universidade(2000). Mestre em Antropologia Social pela Universidade Federal do Rio de Janeiro (1981). Especialista em Antropologia pelo Museu de Antropologia da Universidade de Santa Catarina (1973). Graduada em História pela Universidade Federal de Santana Maria (1972). Graduada em Direito Pela Faculdade de Direito de Santo Ângelo (1975). É professora Titular da Universidade Federal do Pará, junto ao Núcleo de Altos Estudos Amazônicos (NAEA). Atua no Programa de Pós-Graduação em Desenvolvimento Sustentável do Trópico Úmido e no Programa de Pós-Graduação em Gestão Pública e Desenvolvimento.
} 
Amazônia.

\begin{abstract}
The article discusses the relationship between the trajectory of cultural preservation policy in Brazil and the management of archaeological heritage in the Amazon. The objective is to reflect on the effects of the methodological reorientation of heritage policy in the management of archaeological sites in the region in order to discuss the ways in which the government promotes the appropriation of cultural heritage, coupled with the pillars of sustainable development. The analyses are based on the contexts of three regions: Maraca (AP), Calçoene (AP) and Monte Alegre (PA). It was concluded that the methodological reorientation of heritage policy is not a sign of resonance in the formation of dense and effective management of archaeological heritage in these regions. By perpetuating centralized and selective practices, the management of the property highlighted reproduces the traditional logic of heritage policy. This hinders civil society leading and being key actors in the process of appropriation of their cultural environment.
\end{abstract}

Keywords: Archaeological heritage; Management policy;

Amazon.

Introdução

Nas duas últimas décadas, as políticas públicas do setor cultural buscam adequar-se ao amplo conceito de patrimônio cultural instaurado pela Constituição Federal de 1988. Antes limitado a bens de características excepcionais, monumentais e/ou representantes da elite, na atualidade, o conceito engloba o conjunto dos bens culturais (materiais ou imateriais) referentes às identidades coletivas (CHASTEL, 1986; FONSECA, 2009; CHUVA, 2012). Abarca, ainda, a conceituação de meio ambiente.

Essa ampliação semântica provocou a reorientação metodológica da política patrimonial nacional. Desafiada a representar a diversidade cultural do país e a miríade de seus suportes de memória, tal política vem esforçando-se para garantir os dispositivos constitucionais vigentes. De acordo com Brasil (1988), a Constituição vigente garante a todos o acesso aos bens culturais e o usufruto do meio ambiente ecologicamente equilibrado.

Nessa lógica, a política atual do patrimônio valoriza o protagonismo da sociedade civil no processo de apropriação de seu meio ambiente cultural. $E$ isso de modo a dar acesso às fontes da cultura e possibilitar a sustentabilidade dos bens eleitos como representantes da história e memória de determinado povo. A partir dessas modificações 
paradigmáticas, este ensaio se propõe a refletir os reflexos da reorientação metodológica da política patrimonial na gestão dos bens arqueológicos na Amazônia.

Nessa direção, um questionamento é essencial: será que essa reorientação tem se revertido em práticas democráticas e emancipadoras em comunidades locais assentadas ou envoltas a sítios arqueológicos na região? E a partir dessa interrogação, o texto objetiva discutir, ainda, as modalidades com que o poder público fomenta a apropriação do patrimônio arqueológico por parte de comunidades locais e via gestão compartilhada.

Para atingir o objetivo exposto, o texto destacará a realidade vivenciada por três regiões de singular potencial arqueológico na Amazônia, são elas: a região do Maracá (município de Mazagão/AP); o sítio Rêgo Grande (município de Calçoene/AP); e a região de Monte Alegre (Parque Estadual Monte Alegre/PA). Além de destacar o processo de gestão do patrimônio arqueológico dessas áreas, o texto tangencia aspectos concernentes à proteção, manutenção e conservação das mesmas, a fim de suscitar reflexões sobre a efetividade dos pilares da sustentabilidade ambiental nessas regiões.

Adiante, o texto apresenta cinco seções. A primeira delas faz uma visita na significação da expressão "patrimônio cultural" ao longo dos tempos, a fim de aclarar as suas transformações semânticas. Em seguida, discute-se como essas transformações repercutiram no campo da política do patrimônio, a partir do século XXI. Na sequência, aponta-se a base legal que sustenta o tratamento dos bens culturais associado à compreensão de meio ambiente, com atenção especial aos bens arqueológicos. $\mathrm{Na}$ penúltima seção, destaca-se a realidade da gestão compartilhada do patrimônio arqueológico nas três regiões elencadas no parágrafo anterior. Por fim, nas considerações finais, analisa-se como a reorientação metodológica da política patrimonial se reflete na gestão do patrimônio arqueológico na Amazônia.

\section{Patrimônio cultural: dos aspectos materiais aos imateriais}

De acordo com Funari e Pelegrini (2006), atualmente, o significado de patrimônio cultural é amplo e abarca produtos que se relacionam com o sentir, o pensar e o agir dos seres humanos. No entanto, essa diversidade de significados é algo recente e, conforme os autores, as primeiras preocupações com o patrimônio remontam ao surgimento dos Estados-Nações, no século XIX. A consolidação dos mesmos requeria origens, território delimitado e cultura compartilhada. Indo ao encontro com tais interesses, a seleção de um 
conjunto de bens materiais que representassem determinada nacionalidade passou a ser condição sine que non.

Os Estados nacionais necessitavam de um sentimento comum que legitimasse sua criação e fortalecesse sua solidificação enquanto Estado. Assim, elegeram-se produtos nacionais "merecedores de transmissão" para as gerações futuras. No dizer de Pelegrini (2009, p. 20), nesse contexto histórico, a compreensão de patrimônio cultural está restrita "[...] às edificações, aos monumentos e objetos de arte vistos como exemplares autênticos e geniais das riquezas nacionais [...]". Dentro de tais moldes, para que um bem fosse indicado como patrimônio, ele devia ser dotado de valor artístico e histórico ligados à evolução da arte ou da história das elites. Condições essas que acabavam por limitar a atribuição de um sentido histórico às criações de agentes desprovidos de destaque político e econômico.

Pautada nessa perspectiva elitista, ao menos até a primeira metade do século $X X$, a política patrimonial do Brasil privilegiava a preservação de registros memoráveis da história do país, destacando a memória de grupos cultural, econômica e politicamente dominantes. Dessa maneira e segundo Chuva (2012), expressões como "fatos memoráveis" e "excepcional valor" serviram de parâmetro para a política de preservação.

Surgido em 1937, o Serviço do Patrimônio Histórico e Artístico Nacional - SPHAN ${ }^{3}$ foi criado com o objetivo de promover o conhecimento e enriquecimento do patrimônio cultural do país. O primeiro instrumento de proteção elaborado pelo órgão, o Decreto-lei no 25/1937, reforça a compreensão de patrimônio da época e associa o patrimônio nacional a bens excepcionais. Assim, de acordo com Funari e Pelegrini (2006), no país, as primeiras ações em defesa do patrimônio nacional incluiriam a seleção de edifícios do período colonial, em estilo barroco e palácios governamentais, considerando sua relação com a história oficial da nação, elevando-se a arquitetura à condição de marca capaz de promover a imagem de solidez do Estado brasileiro.

Contudo, no decorrer da trajetória do órgão do patrimônio, as normas de proteção à cultura e de seus bens memoráveis, assim como a concepção de patrimônio cultural foram paulatinamente se alargando até alcançar o amplo conceito da Constituição Federal de 1988. Pela primeira vez um texto constitucional contempla como patrimônio a dimensão material e imaterial da cultura, bem como faz referência à identidade e à memória dos diferentes grupos formadores da sociedade brasileira. É assim que dispõe o seu artigo 216, caput:

\footnotetext{
${ }^{3}$ Nome do atual IPHAN até 1946.
} 
Art. 216. Constituem patrimônio cultural brasileiro os bens de natureza material e imaterial, tomados individualmente ou em conjunto, portadores de referência à identidade, à ação, à memória dos diferentes grupos formadores da sociedade brasileira, nos quais se incluem:

I- as formas de expressão;

II- os modos de criar, fazer e viver;

III- as criações científicas, artísticas e tecnológicas;

IV- as obras, objetos, documentos, edificações e demais espaços destinados às manifestações artístico-culturais;

V- os conjuntos urbanos e sítios de valor histórico, paisagístico, artístico, arqueológico, ecológico e científico (BRASIL, 1988).

Nesses termos, torna-se claro que, a partir da CF/1988, o patrimônio cultural nacional não está mais restrito aos bens materiais vinculados à elite. Outras formas de expressão são consideradas nos incisos do artigo mencionado, valorizando, de tal maneira, a miscigenação que predomina na formação do povo brasileiro. Não limitando-se a alargar a definição de patrimônio,o texto constitucional também amplia as responsabilidades pela preservação do mesmo, ao atribuir ao poder público, com a colaboração da comunidade, a promoção e proteção dos bens culturais.

Para Brusadin (2011, p. 33), a opção pela expressão "[...] patrimônio cultural [...]" fez com que a CF/1988 se demonstrasse inovadora em comparação a textos constitucionais estrangeiros, tais como o espanhol, que utiliza, nesta expressão, os termos patrimônio artístico e patrimônio histórico. Essa transposição de conceitos objetivou superar, ainda conforme Brusadin (2011, p. 33), uma concepção puramente arquitetônica de patrimônio em favor de uma concepção cultural capaz de abranger "[...] todas as expressões simbólicas da memória coletiva, constitutivas da identidade de um lugar, de uma região e de uma comunidade".

Ao reconhecer os aspectos materiais e imateriais da cultura, a CF/1988 oferta, portanto, uma concepção ampliada de patrimônio cultural, na qual o termo pode ser definido como:

\footnotetext{
[...] algo apto a satisfazer uma necessidade de cunho cultural e que se caracteriza por seu valor próprio, independentemente de qualquer valor pecuniário, de ser testemunho da criação humana, da civilização, da evolução da natureza ou da técnica, não se esgotando em seus componentes materiais, mas abarcando sobretudo o "valor" emanado de sua composição, de suas características, utilidade, significado etc. (MARCHESAN, 2007, p. 39).
}

No entanto, segundo Meneses (2012), ao contrário do que muitos pensam, a grande inovação proporcionada pela CF/1988 não é a inserção dos bens imateriais ao conceito do 
termo discutido. A transformação principal ofertada pela Carta Magna é, nos termos de Meneses (2012, p. 33), o "[...]deslocamento da matriz[...]", o que significa que comunidades locais ganham mais autonomia para eleger suas referências culturais. Assim, o Estado deixa de ser o protagonista nesse processo.

\section{O deslocamento da matriz e apolítica patrimonial atual}

A proposição de um "[...]deslocamento da matriz[...]" (MENESES, 2012, p. 33) no trato dos recursos culturais sinaliza uma tentativa de superação do paradigma tradicionalista ${ }^{4}$ para o participacionista (CANCLINI, 1994), no qual privilegia-se o uso social do patrimônio. No campo das políticas públicas, os procedimentos adotados a partir desse paradigma possuem como princípios fundamentais a mínima interferência do Estado e a máxima participação popular. Logo, ao contrário das práticas que marcaram as ações tradicionais da política do patrimônio, a metodologia preservacionista desse cenário considera todos os bens culturais que sejam marcos de memória e identidade para um grupo social.

Em virtude do desmonte das estruturas vinculadas à cultura na década de 1990 (FONSECA, 2005), os aspectos inovadores da CF/1988 só são percebidos na década seguinte. Conforme Porta (2012), é a partir da década de 2000 que se observam inovações na política de preservação do Brasil. As diretrizes principais que ilustram essas mudanças são:

1. a atualização do conceito de patrimônio, adequando-o à diversidade cultural brasileira;

2. a formulação de diretrizes para orientar a ação institucional, tendo como foco o envolvimento da sociedade, a promoção do desenvolvimento local e a potencialização das possibilidades de fruição do patrimônio cultural;

3. a abertura para novas áreas de atuação, de forma de abranger os diferentes legados da cultura brasileira;

4. a formulação e a implantação de novos instrumentos de ação;

5. a revisão das metodologias de trabalho;

6. o fortalecimento do órgão nacional de preservação para dar suporte à ampliação do campo de ação;

7. o esforço para construir instrumentos de ação conjunta e de gestão compartilhada do patrimônio entre União, estados e municípios;

8. o progressivo e substancial aumento do investimento em preservação de bens culturais (PORTA, 2012, p.7).

A partir das diretrizes elencadas, observa-se que, para além da superação do

\footnotetext{
${ }^{4}$ No qual o patrimônio é sinônimo de monumentos e/ou obras de arte vinculados a elite.
} 
processo tradicional de patrimonialização, a atual política patrimonial busca: a) representar a formação plural da sociedade brasileira; b) facilitar a participação da sociedade na apropriação dos recursos da cultura; b) garantir a sustentabilidade dos bens culturais nacionais; c) permitir o acesso e usufruto dos bens culturais a todos; e d) inserir o patrimônio cultural na pauta das políticas públicas de desenvolvimento do país.

Para dar solidez aos atuais objetivos da política patrimonial, o IPHAN tem ampliado seu campo de atuação no Brasil, a fim de dar visibilidade a todos os grupos formadores da identidade cultural brasileira, inclusive àqueles que foram postos na margem pela prática tradicional da instituição. A renovação metodológica da política preservacionista promove a valorização do patrimônio a partir de uma dimensão não mais reducionista, nem apegada à historiografia tradicional. A diminuição pela predileção da preservação dos chamados bens de pedra e cal abriu espaço para a valorização dos bens culturais desprovidos de monumentalidade e excepcionalidade.

Desse modo, conforme Vasconcelos (2009), diferentemente da realidade observada na tradição, o sentido histórico de pessoas comuns vai deixando de ser suprimido. Por sua vez, o patrimônio material ganha contornos novos. Assim, deixa de constituir bens isoladamente considerados, para, então, fazer parte do contexto físico e social onde se encontram.

Definido como parte integrante do patrimônio cultural pelo artigo 216 -V da CF/1988, o patrimônio arqueológico insere-se nesse contexto novo e há de buscar, na opinião de Vasconcelos (2009), trilhar caminhos novos a fim de uma conservação melhor e aproveitamento. "Despertar o interesse da comunidade é ponto fundamental para esse processo" (VASCONCELOS, 2009, p. 332). Devidamente envolvida, a comunidade tem potencial para desencadear ações articuladas que tornam possível a valorização e respeito pela materialidade dos bens arqueológicos, de forma que estes passam a ser reconhecidos como parte integrante da cultura local e elementos de uma memória coletiva.

\section{Meio ambiente e patrimônio arqueológico}

Pari passu à essas reorientações metodológicas, a ampliação semântica de patrimônio cultural o inseriu ao entendimento de meio ambiente e, por consequência, os bens culturais ganham a tutela da legislação ambiental. Assim, conforme Miranda (2006), meio ambiente e patrimônio cultural são aspectos inseparáveis sob a ótica do direito. Isso 
justifica-se porque, na atualidade, meio ambiente não mais se restringe a aspectos unicamente naturalísticos; para Miranda (2006, p. 12), ele "[...] comporta uma conotação abrangente, holística, compreensiva de tudo o que cerca e condiciona o homem em sua existência, no seu desenvolvimento na comunidade a que pertence e na interação com o ecossistema que o cerca".

Esclarecedor é o raciocínio de Soares (2007), para quem meio ambiente e patrimônio cultural compõem um "macrobem" enorme, um patrimônio "uno", formado por elementos naturais e culturais, associados à dignidade da pessoa humana e responsáveis por imprimir a qualidade de vida. Desse modo e de acordo com o meio especializado, a tutela dos bens culturais insere-se no conceito de direito fundamental de terceira geração, pois a proteção desses bens atende a humanidade como um todo (direito difuso) (MIRANDA, 2006; PÉREZ LUÑO, 2012). Ainda de acordo com esses autores, essa tutela preserva a sua memória e seus valores, garantindo a sua transmissão para as futuras gerações.

A consideração da indivisibilidade entre meio ambiente e patrimônio cultural fez com que especialistas de áreas diversas observassem o patrimônio cultural como um veículo de inclusão social, cidadania, proteção ambiental e desenvolvimento local. Nessa lógica, os bens arqueológicos tornam-se, portanto, vetores de direitos sociais; precisamente, com potencial para suscitar ações de valorização e respeito pela cultura de povos pretéritos.

Segundo Dantas (2015, p. 46), ao estar contido na compreensão de meio ambiente, o patrimônio arqueológico constitui-se como um bem público da União Federal, inalienável e imprescritível. É, ainda, um bem de proteção qualificada, pois como enfatiza Soares (2007), é gerido por normas administrativas, por legislações específicas e pela legislação ambiental. Desse modo, a legislação estabelece um sistema de cogestão envolvendo instituições federais, arqueólogos, instituições de guarda e empreendedores a fim da otimização de ações para o melhor conhecimento, preservação e promoção desses bens.

Todavia, a existência de um rol amplo de instrumentos de proteção não é garantia para a proteção e preservação do patrimônio arqueológico na Amazônia. Na região, de fato, esse bem é ameaçado pelo vandalismo, pela devastação de áreas florestadas para atividades antrópicas, pelo pouco conhecimento da expressividade da herança cultural dos bens arqueológicos e pelo desconhecimento da legislação de proteção. Por conta dessa vulnerabilidade, é que a gestão compartilhada com comunidades locais justifica-se como estratégia adequada para a preservação desse bem cultural na região. 
Se visibilizadas no gerenciamento do patrimônio em questão, além de somar para a proteção do mesmo, essas comunidades podem contribuir na gestão do legado históricocultural e, ainda, adquirir meios de sustentabilidade. Destarte e de acordo com Ferreira (2006), a gestão compartilhada constitui-se na integração do poder público, iniciativa privada e sociedade, com vistas à otimização de ações. Nas palavras do autor, esse modelo de gestão:

[...] promove a interação dessas instâncias, de forma sinérgica, possibilitando um novo meio de perceber e intervir no sistema objeto da cooperação. Assim, identificase um modelo de gestão que busca a interação entre os diversos entes sociais objetivando, através da cooperação entre os mesmos, um desenvolvimento sustentável com a participação coletiva (FERREIRA, 2006, p. 35).

Em se tratando da gestão compartilhada do patrimônio arqueológico, Pardi (2002) a define como um conjunto de ações desempenhadas por uma variedade de atores, cuja junção de esforços vislumbra identificar, promover e preservar aquilo que se entende como a produção documental dos povos antigos. A partir desse viés, esse tipo específico de gestão engloba:

[...] um conjunto de estudos, análises, reflexões e ações que buscam equacionar informações sobre os bens culturais, os parceiros envolvidos, as estruturas e as questões econômicas inerentes, visando otimizar o uso e o retorno à atual geração, a valorização e difusão, bem como preservação dos sítios ou blocos testemunhos, do acervo gerado, da documentação e do conhecimento produzido para as gerações futuras (PARDI, 2002, p.20).

Pelo exposto, compreende-se que a gestão compartilhada do patrimônio arqueológico é capaz de possibilitar concomitantemente o usufruto social dos bens culturais, o desenvolvimento local, a sustentabilidade e a proteção do meio ambiente cultural.

\section{A inserção de comunidades na gestão do patrimônio arqueológico}

Em virtude dos avanços conceituais e ampla proteção jurídica, a partir do século XXI, se observam na Amazônia iniciativas do poder público para o fomento da apropriação do patrimônio arqueológico por parte de comunidades locais. Em meio a essas iniciativas, destaca-se o Projeto de Musealização de Sítios Arqueológicos na Amazônia, elaborado pelo IPHAN. Isso ocorreu entre os anos de 2009-2010 e objetivou a criação de infraestrutura adequada em sítios localizados em áreas de alto potencial arqueológico. 
A intenção do projeto era fazer com que as comunidades locais não apenas se beneficiassem com a socialização dos sítios, mas também compartilhassem de sua gestão. Assim, elas assumiriam o seu papel na preservação dos mesmos e dos empreendimentos construídos. O projeto selecionou três áreas, duas no estado do Amapá e uma no Pará, são elas: Maracá (AP), Calçoene (AP) e Monte Alegre (PA).

Localizada no sul do estado do Amapá, no município de Mazagão, a região do Maracá apresenta a ocorrência abundante de sítios pertencentes à fase arqueológica Maracá. Nessa região, o projeto abrangeu três sítios: Abrigo do Tracuá, ${ }^{5}$ Buracão do Laranjal $^{6}$ e Gruta do Veado ${ }^{7}$. Conforme Figueiredo et al. (2010), além de proporcionar a possibilidade de visitação controlada nesses sítios, o projeto previu a construção de um centro cultural na Vila Maracá. O espaço foi planejado para permitir o desenvolvimento de atividades de educação patrimonial envolvendo as escolas locais e os visitantes. Ao pensarse na dinamização econômica da vila, o projeto não previu lanchonetes e/ou restaurantes no centro cultural, assim, os visitantes seriam direcionados aos serviços ofertados pelos moradores locais.

Situado ao norte do estado, o município de Calçoene está contido em uma área com importância histórica significativa para o Amapá. No passado, essa região foi palco de disputas territoriais entre Brasil e França e chegou a conter, no século XIX, uma República Independente denominada Cunani (SARNEY; COSTA, 1999). No município como um todo, há a ocorrência de muitos sítios arqueológicos da fase Aristé. Dentre eles, destaca-se o sítio Rêgo Grande, que vem sendo comparado por Cabral e Saldanha (2011) ao Stonehenge, na Inglaterra ${ }^{8}$. As estruturas megalíticas e o potencial turístico desse sítio justificaram sua seleção pelo projeto de musealização do IPHAN.

Denominado Parque Arqueológico de Calçoene, o projeto agrega a construção de um museu, na cidade de Calçoene, e uma estrutura moderna no sítio composta por passarelas. Por meio destas, os visitantes teriam acesso às rochas megalíticas sem tocálas. De acordo com Figueiredo et al. (2010), o projeto almejou o fortalecimento de um turismo de base comunitária, para que a comunidade pudesse apropriar-se dos bens arqueológicos.

\footnotetext{
Sítio com pinturas rupestres.

Sítio com pinturas rupestres.

Sítio cemitério pertencente à fase Maracá, no qual foram encontradas inúmeras urnas funerárias.

8 O sítio Rêgo Grande localiza-se a dezesseis quilômetros da cidade de Calçoene, sede do município onde está o Distrito de Cunani. Cabral e Saldanha (2011) indicam existir nesse sítio mais de 150 blocos de rocha. Alguns deles superam três metros de comprimento e estão fincados no topo de uma elevação formando um círculo. Essas características levaram os arqueólogos a comparar o local ao Stonehenge, na Inglaterra.
} 
Por sua vez, a região de Monte Alegre localiza-se a oeste do estado do Pará, em um território considerado pelo meio especializado como um dos mais antigos assentamentos populacionais da Amazônia (FIGUEIREDO et al., 2010). Em seus limites, há a ocorrência de sítios arqueológicos importantes. Nessa região, o IPHAN selecionou dois sítios para serem musealizados e são eles: o Pedra do Mirante e o Serra da Lua, ambos com pinturas rupestres e localizados dentro do Parque Estadual Monte Alegre (PEMA). Assim como nas regiões de Maracá e Calçoene, o projeto de musealização dos sítios de Monte Alegre privilegiou o estabelecimento de parcerias com as comunidades locais, com vistas à apropriação do patrimônio arqueológico e o desenvolvimento local.

Observa-se que o Projeto de Musealização de Sítios Arqueológicos na Amazônia constituiu-se como uma política pública com forte potencial para fazer com que as comunidades locais das áreas selecionadas pudessem apropriar-se de seu patrimônio arqueológico. Contudo, segundo informações de Djalma Santiago (informação verbal) ${ }^{9}$, essa potencialidade não foi o suficiente para consolidar o apoio do poder público na execução do projeto. $\mathrm{O}$ não cumprimento de acordos e parcerias firmados junto aos governos estaduais do Amapá e Pará, bem como com as prefeituras dos municípios envolvidos tem inviabilizado, até então, a sua execução.

Conforme Silva (2014a), os projetos elaborados para Maracá e Calçoene estão parados na Agência de Desenvolvimento do Amapá (ADAP). Enquanto isso, a realidade observada nas comunidades locais dessas duas áreas revela contextos de abandono e negligência do direito de acesso e usufruto dos bens culturais a todos, tal como assevera a CF/1988.

Na região de Maracá, por exemplo, Campos (2008) evidencia que o único instrumento de gestão utilizado são as autorizações de pesquisa concedidas pelo IPHAN. O autor revela também que, apesar de a maioria das famílias dessa localidade estar assentada sobre sítios ou no entorno deles, $60 \%$ delas desconhecem as pesquisas realizadas no lugar; $52,78 \%$ não sabem da existência de sítios arqueológicos e 68, 52\% nunca tiveram acesso a eles.

Ele destaca, ainda, o quadro de vulnerabilidade econômica e social em que vivem essas famílias. A economia do lugar não consegue melhorar as condições de vida de quem lá vive, é uma economia de subsistência, onde a principal atividade é a agricultura $(47,9 \%)$,

\footnotetext{
${ }^{9}$ Djalma Santiago é técnico do IPHAN no Amapá. Informação repassada em diálogo com a autora, em 16/09/2016, na sede do IPHAN-AP.
} 
seguida da coleta (23\%) e da prestação de serviços (20,93\%). A renda familiar da parte maior dos moradores $(63,89 \%)$ não ultrapassa um salário mínimo. No que se refere ao nível de escolaridade, a população, em geral, possui somente as primeiras séries do Ensino Fundamental. Logo, como sinaliza Campos (2008), em se tratando de sustentabilidade, a realidade do Maracá deixa a desejar nas questões ambientais, socioeconômicas e culturais.

No município de Calçoene, onde está o sítio Rêgo Grande, ${ }^{10}$ os problemas continuam. Silva (2014a) aponta a ausência de uma logística mínima para a manutenção do sítio, fato que dificulta o seu acesso e usufruto social. Soma-se a esse aspecto, dificuldades para o guarda-parque do local $^{11}$ se manter nele com o a devida segurança e impedir a invasão da área por saqueadores.

Segundo Silva (2014b), ${ }^{12}$ no ano de 2014, além de ameaçarem a integridade física do guarda-parque, esses saqueadores invadiram o sítio, depredaram seus espaços e ainda levaram móveis e equipamentos de comunicação da base que foi construída no local pelo governo do estado. Acrescente-se também, a ausência de manutenção do ramal que dá acesso ao sítio. De acordo com relatos de Silva (2014b), no período invernoso, é comum o ramal ficar intrafegável e o sítio isolado por conta dos atoleiros. Destaca-se que, até o presente, esse ramal não é pavimentado, apesar do local receber visitas constantes de turistas brasileiros e estrangeiros.

Na região de Monte Alegre, no Pará,para além da vulnerabilidade a problemas de ordem natural, os sítios de pinturas rupestres estão totalmente expostos à ação antrópica. No dizer de Andrade (2012), a entrada de visitantes na área onde estão os sítios não possui nenhum tipo de controle. Logo, mesmo contidos dentro de um espaço ambiental protegido (o PEMA), os sítios são depredados por conta dessa ausência de monitoramento.

Conforme a autora, no sítio Pedra do Mirante, ${ }^{13}$ as pichações e as fuligens de queimadas são os problemas mais comuns. Acrescente-se a eles a construção inadequada de escadas pela Secretaria Estadual de Meio Ambiente do Estado do Pará (SEMA). Construídas para facilitar o acesso até o topo da rocha, as escadas são considerada por Andrade (2012, p. 82) como "[...] uma ação contraditória do órgão gestor, pois não existe

\footnotetext{
${ }_{11}^{10} \mathrm{O}$ que vem sendo comparado ao Stonehenge.

11 Aliás, existe apenas um guarda-parque que é Lailson Camelo da Silva, popularmente conhecido como Garrafinha (62 anos).

${ }_{12}$ Guarda-parque do sítio Rêgo Grande, em entrevista concedida à autora, em 05/01/2014, em Calçoene-AP, na casa do entrevistado.

${ }^{13}$ Localizado na porção oriental do topo da Serra do Ererê, a uma altura aproximada de 200 metros em relação ao rio Amazonas. Trata-se de um sítio de pinturas rupestres a céu aberto, que situa-se em um bloco arenítico de grandes proporções.
} 
controle com relação à visitação no PEMA e essa estrutura facilitaria o acesso aos visitantes". A autora explica que a ação não teve a anuência do IPHAN e nem o acompanhamento de um arqueólogo. Logo, a estrutura é intrusiva ao sítio.

O sítio Serra da Lua $^{14}$ possui problemas ainda mais graves. Nele, de acordo com Andrade (2012), registrou-se um número superior de agressões ao suporte rochoso causadas por: pichação, risco, raspagem, picoteamento, fuligem e até tiro. Esse último tipo de agressão (tiro) não é relatada em nenhuma outra área da região. Porém, no Serra da Lua existem figuras semelhantes a alvos. Assim, essas figuras passaram a ser utilizadas de modo inadequado para a prática de tiro, o que resulta na descaracterização irreversível das pinturas rupestres existentes nas rochas.

Em situação de vulnerabilidade econômica e social, as comunidades do PEMA demonstram não agregar valor ao patrimônio arqueológico. Para Andrade (2012), embora as comunidades do parque saibam da existência das pinturas, para a maioria delas, essas pinturas não são importantes. Além disso, a ausência de efetivação de políticas públicas voltadas para a apropriação do patrimônio arqueológico resulta na descrença das comunidades na possibilidade de desenvolvimento local fundado no potencial ambiental e cultural da região.

Desacreditadas das promessas de desenvolvimento sustentável, as comunidades dessa área de proteção ambiental questionam os objetivos de criação do PEMA. Impossibilitados de praticar a caça, a agricultura e a extração de madeira, bem como de usufruir os benefícios advindos da musealização dos sítios arqueológicos, muitos moradores estão descrentes quanto à essa política. Assim, eles visualizam o parque como um obstáculo para a dinamização econômica de Monte Alegre.

Logo, é evidente que, apesar dos avanços conceituais, proteção jurídica ampla e planejamento de estratégias de gerenciamento, a participação ativa da sociedade civil no processo de gestão do patrimônio arqueológico ainda é limitada na Amazônia. Situação que não condiz com a política patrimonial atual. Na região, embora existam projetos pautados na gestão compartilhada e com objetivos sustentáveis, essas iniciativas possuem dificuldades para sair do plano teórico.

\section{Considerações finais}

\footnotetext{
14 Sítio a céu aberto com pinturas rupestres. Localiza-se no flanco oeste da Serra do Ererê, a aproximadamente 100 metros de altitude em relação ao rio Amazonas. As pinturas rupestres estão distribuídas ao longo de um paredão arenítico abrupto, que contorna essa serra na sua ponta oeste.
} 
Ao se desprender da concepção de uma identidade nacional única, o texto constitucional de 1988 lança as bases para a reorientação metodológica da política patrimonial nacional. Desafiada a proporcionar o uso social de bens culturais, a política patrimonial em curso esforça-se para promover o "[...] deslocamento da matriz [...]" (MENESES, 2012, p. 33). Também, a mesma busca possibilitar o protagonismo da sociedade civil no processo de gestão do patrimônio cultural.

Não obstante, em se tratando da gestão do patrimônio arqueológico na Amazônia, esse protagonismo parece estar preso ao campo retórico. De fato, o mesmo não afeta o gerenciamento desse bem de maneira efetiva. Desse modo, é clara a incoerência entre o discurso da atual política patrimonial e a real situação da gestão do patrimônio arqueológico na região.

É inegável que a reorientação metodológica da política patrimonial é uma conquista para os bens culturais marginalizados pela política cultural que antecedeu a redemocratização do país. Não é intenção desse texto sustentar o contrário; precisamente, porque a partir dessa reorientação, bens culturais desprovidos de monumentalidade e ligados a grupos distintos da elite ganharam mais visibilidade e puderam entrar no rol dos bens protegidos pelo Estado.

No entanto, observa-se que, até então, as diretrizes vigentes da política patrimonial não sinalizam ressonância na constituição de uma gestão densa e efetiva para o patrimônio arqueológico na Amazônia. Ao perpetuar práticas centralizadoras e seletivas, a gestão do bem destacado reproduz a lógica tradicional da política de preservação. Dificulta, assim, que a sociedade possa conduzir e protagonizar o processo de gestão de seu meio ambiente cultural.

Compreende-se, portanto, que a consideração de meio ambiente e patrimônio cultural como um bem "[...] uno [...]" (SOARES, 2007, p. 15) e indispensável para o exercício da cidadania continua a ofertar desafios enormes para o poder público. Na Amazônia, comunidades locais residentes em áreas de elevado potencial arqueológico possuem dificuldades para conhecer, assimilar e usufruir a herança material deixada por povos pretéritos. Logo, o acesso ao patrimônio arqueológico está longe de ser tratado como um direito fundamental. Consequentemente, o desafio de incluir, proteger e difundir as referências culturais dos variados grupos formadores da sociedade brasileira permanece. 
Essa permanência está diretamente vinculada ao espaço ocupado por essa categoria específica de patrimônio na formação da identidade cultural do país. Como exposto ao longo do texto, em sua gênese, a formação dessa identidade privilegiou a memória e os feitos dos "grandes homens", das "grandes nações". Assim, a dinâmica patrimonial negligenciou a memória dos povos nativos, relegando-a para o esquecimento.

\section{Referências}

ANDRADE, M. N. de. Conservação integrada do patrimônio arqueológico: uma alternativa para o Parque Estadual Monte Alegre - Pará - Brasil. Teresina, 2011. 193f. Dissertação (Mestrado em Antropologia e Arqueologia) - Universidade Federal do Piauí, 2012.

BRASIL. Constituição da República Federativa do Brasil de 05 de outubro de 1988. Disponível em: <www.planalto.gov.br>. Acesso em: 11 de set. 2016.

BRUSADIN, L. B. A dinâmica do patrimônio cultural e o Museu da Inconfidência Mineira em Ouro Preto (MG). Franca, 2011. 213 f. Tese (Doutorado em História). Universidade Estadual Paulista, 2011.

CABRAL, M. P.; SALDANHA, J. D. de M. O caminho das pedras. Revista de História da Biblioteca Nacional, no 65, p. 52-56, fevereiro, 2011.

CAMPOS, R. I. R. Sustentabilidade, turismo e gestão do patrimônio arqueológico: limites e possibilidades no Maracá (AP) e Serra dos Martírios/ Andorinhas (PA). Belém, 2008. 395 f., il. Tese (Doutorado em Desenvolvimento Sustentável do Trópico Úmido) Universidade Federal do Pará, 2008.

CANCLINI, Néstor Garcia. O Patrimônio Cultural e a construção imaginária do nacional. Revista do Patrimônio Histórico e Artístico, Rio de Janeiro: IPHAN, n.ำ 23, 1994.

CHASTEL, R. La notion de patrimoine. In: NORA, P. Leslieux de mémoire. V. 2. Paris: Gallimard, 1986. p. 405-449.

CHUVA, M. Preservação do patrimônio cultural no Brasil: uma perspectiva histórica, ética e política. In: CHUVA, M; NOGUEIRA, A. G. R. (Org.). Patrimônio cultural: políticas e perspectivas de preservação no Brasil. Rio de Janeiro: FAPERJ, 2012.p. 67-78.

DANTAS, F. S. O patrimônio cultural protegido pelo Estado Brasileiro. In: CAMPOS, J. B.; PREVE, D. R.; SOUZA, I. F. (Org.). Patrimônio cultural, direito e meio ambiente: um debate sobre a globalização, cidadania e sustentabilidade. Curitiba: Multideia, 2015.p. 3153.

FERREIRA, M. R. L. Gestão compartilhada e cidadania: um estudo da experiência do "Pacto do Novo Cariri". João Pessoa, 2006. 215 f. Dissertação de Mestrado. Universidade Federal da Paraíba. 2006. 
FIGUEIREDO, Silvio José Lima de; PEREIRA, Edithe da Silva; BEZERRA, Marcia. et al. Relatório do projeto básico e especificações técnicas para elaboração de projetos de socialização de sítios arqueológicos na Amazônia: musealização, educação e turismo. NAEA/UFPA, Belém, 2010.

FONSECA, M. C. L. O patrimônio em processo: trajetória da política federal de preservação no Brasil. 2. ed. rev. ampl. Rio de Janeiro: Editora UFRJ; MINC - IPHAN, 2005.

Para além da pedra e cal: por uma concepção ampla de patrimônio cultural. In: ABREU, R; CHAGAS, M. (Org.). Memória e patrimônio: ensaios contemporâneos. 2. ed. Rio de Janeiro: Lamparina, 2009.p. 59-79.

FUNARI, P. P.; PELEGRINI, S. de C. A. Patrimônio histórico e cultural. Rio de Janeiro: Jorge Zahar Ed, 2006.

MARCHESAN, A. M. A tutela do patrimônio cultural sob o enfoque do direito ambiental. Livraria do advogado, 2007.

MENESES, U. T. B. de. O campo do patrimônio cultural: uma revisão de premissas. In: SUTTI, W. (Coord.). I Fórum Nacional do Patrimônio Cultural: sistema nacional de patrimônio cultural - desafios, estratégias e experiências para uma nova gestão. Brasília: IPHAN, 2012.p. 25-39.

MIRANDA, M. P. de S. Tutela do patrimônio cultural brasileiro: doutrina, jurisprudência, legislação. Belo Horizonte: Del Rey, 2006.

PARDI, M. L. Gestão do Patrimônio arqueológico, documentação e política de preservação.Goiânia, 2002.289 f.Dissertação de Mestrado. Instituto Goiano de Pré-História, 2002.

PELEGRINI, S. de C. A. Patrimônio cultural: consciência e preservação. São Paulo: Brasiliense, 2009.

PÉREZ LUÑO, A. E. Los derechos humanos enla sociedade tecnológica. Madrid: Editorial Universitas, 2012.

PORTA, P. Política de preservação do patrimônio cultural no Brasil: diretrizes, linhas de ação e resultados: 2000/2010. Brasília: IPHAN/Monumenta, 2012.

SARNEY, J.; COSTA, P. La RépubliqueduCounani. In SARNEY, J.; COSTA, P.Amapá: a terra onde começa o Brasil. Brasília: Senado Federal; Conselho Editorial, 1999. p. 137-140. (Coleção Brasil 500 anos).

SILVA, A. C. R. Programa de preservação do patrimônio arqueológico do Amapá (2005/2013): um modelo de gestão de política pública de preservação cultural. Macapá, 2014. 139 f., il. Dissertação (Mestrado em Direito Ambiental e Políticas Públicas) Universidade Federal do Amapá, 2014a. 
SILVA, L. C. da.Entrevista concedida à Ana Cristina Rocha Silva sobre a gestão do sítio Rêgo Grande. Calçoene. 05. jan. 2014b. (Anotações de A. C. R. Silva; arquivo pessoal).

SOARES, I. V. P. S. Proteção jurídica do patrimônio arqueológico no Brasil: fundamentos para efetividade da tutela em face de obras e atividades impactantes. Erechim: Halibis, 2007.

VASCONCELOS, L. B. Educação patrimonial e a tutela do patrimônio arqueológico. In: SOARES, I. V. P.,et al. (Org). Arqueologia, direito e democracia. Erechim: Habilis, 2009.p.329-362. 